\title{
CRÍTICA AO PERSONALISMO ÉTICO DA CONSTITUIÇÃO DA REPÚBLICA E DO CÓDIGO CIVIL. EM FAVOR DE UMA ÉTICA BIOCÊNTRICA
}

\author{
CRITICS TO THE ETHICAL PERSONALISM IN THE CONSTITUTION OF REPUBLIC AND THE CIVIL \\ CODE IN BENEFIT OF A BIOCENTRAL ETHICS
}

Antonio Junqueira de Azevedo*

\begin{abstract}
Resumo:
$\mathrm{O}$ artigo critica o personalismo ético que supõe radical separação entre homens e animais, e não valoriza a vida em geral. O texto procura afirmar o fundamento biológico da ética, em três emergências sucessivas da evolução.

Palavras-chaves: Ética. Biocentrismo. Personalismo Ético.
\end{abstract}

\begin{abstract}
:
This article criticizes the ethical personalism which supposes a radical separation between man and animals and do not value life in general. This text aims to affirm the biological foundings of ethics in three successive rises of evolution.
\end{abstract}

Keywords: Ethics. Biocentrism. Ethical Personalism.

\section{Personalismo ético}

O Direito Civil brasileiro, desde o século XIX, tem no personalismo ético sua diretriz principal. Isto se deve à influência pandetista que nos levou a ter no primeiro Código Civil, e até mesmo antes dele, na Consolidação das Leis Civis, uma Parte Geral que abre com o livro Das Pessoas. No Código Civil, de 1916, o art. $2^{\circ}$ era um verdadeiro manifesto da igualdade entre as pessoas: "Todo homem é capaz de direitos e obrigações na ordem civil". "Todo homem", quer dizer, todo homem, toda mulher, toda criança, todo idoso, qualquer um, qualquer que seja a idade, a etnia, a nacionalidade, a cor da pele, a religião, o patrimônio, o status social ou o grau de cultura: “todo homem”. Também o Código Civil, de 2002, em seu art. $1^{\text {}}$, com o mesmo espírito, proclama: “Toda pessoa é capaz de direitos e deveres na ordem civil".

\footnotetext{
Professor Titular de Direito Civil da Faculdade de Direito da Universidade de São Paulo; ex-Diretor da Faculdade de Direito da Universidade de São Paulo. Diretor da Faculdade de Direito de Ribeirão Preto da Universidade de São Paulo. Membro da Comissão de Publicação da Revista da Faculdade de Direito da Universidade de São Paulo.
} 
O personalismo ético se enraíza nas idéias iluministas do século XVIII e especialmente na formulação de Kant, conforme é amplamente reconhecido na doutrina civilista alemã. ${ }^{1} \mathrm{O}$ texto básico de Kant no tema é aquele que se encontra nos "Fundamentos da Metafísica dos Costumes", em que o citado filósofo depois de dizer que os seres humanos são fins, e não meios, afirma que as pessoas têm dignidade, enquanto tudo o mais tem preço. ${ }^{2}$ Entre parêntesis, vale lembrar com Hans Jonas, que as habituais considerações lógico-formais de Kant não são o pressuposto mais coerente para sua afirmação axiológicomaterial sobre o valor da pessoa humana. ${ }^{3}$ Em todo caso, a orientação ética, centrada na pessoa humana, era já um fato próprio do Direito Civil desde as codificações do século XIX. Daí porque alguns autores como Miguel Reale escreveram que o Código Civil é a verdadeira Constituição do homem comum. ${ }^{4}$

A Constituição da República, de 1988, como uma espécie de terceira dimensão do direito posto, na sua diretriz de incorporar o Direito Público e o Direito Privado, absorveu a idéia do personalismo ético com grande força. Sobre seu art. $1^{\circ}$, que contém os princípios fundamentais da República, embora sejam cinco os seus incisos, tem sido freqüente a afirmação de que a dignidade da pessoa humana (é o inciso III) constitui a determinação por excelência de todo o texto constitucional. Certamente essa asserção corresponde à importância que, há pelo menos 60 anos, vêm sendo dada aos "Direitos Humanos". Embora, portanto, a questão seja hoje constitucional e os juristas da dignidade de pessoa humana sejam muitos, e notáveis, talvez já estejamos em tempo - essa é a razão de ser desse artigo - de ousar iniciar um movimento de revisão do tema, personalismo ético, para introduzir retificações na idéia predominante como vem sendo apresentada, de dignidade da pessoa humana.

Cf. LARENZ, Karl. Derecho civil: parte general. Tradução de Miguel Izquierdo y Macías. Picavea. Madri: Ed. Revista de Derecho Privado, 1978. § $2^{\circ}$.

2 KANT, Emanuel. Des fondaments de la métaphysique des moeurs. Tradução de J. Barni. Paris: Livr. Philosophique de Ladrange, 1848. p. 69 e ss. (homem, fim em si) e p. 80 (dignidade x preço).

3 JONAS, Hans. Le principe responsabité: une éthique pour la civilisation technologique. Tradução de Jean Greisch. Paris: Flamarion, 2000 (com base na 3. ed. de 1995), p. 177 (ex- p. 170).

4 REALE, Miguel. Apresentação do Projeto de Código Civil ao Ministro da Justiça, 1984, no título "Diretrizes metodológicas". FRANÇA, Rubens Limongi. Direito civil constitucional. Revista do Tribunal de Justiça do Pará, Pará, n. 55, 1992), baseado em aula de abertura do ano letivo, com o título "O Direito Civil Constitucional", em que o conteúdo não é o "Direito Civil Constitucional", sustentado hoje por alguns autores (Perlingieri, Tepedino, Celina de Moraes, etc), e sim, a idéia de que o Direito Civil, por força especialmente da Lei de Introdução e da Parte Geral, é um supra-direito. 


\section{A deficiência antropocêntrica}

Tomado desse espírito blasfemo, penso que todos os grandes filósofos, para alegria dos humildes, cometem grandes erros (além de pequenos). O erro de Kant foi o de considerar que toda a vida não-humana, a vida em geral, e, em especial, a vida dos animais, era desprezível, sem dignidade, coisa! ${ }^{5}$ Com a boa vontade de seu tempo exclusivamente para com os seres humanos, o pensamento de Kant acaba por justificar a destruição da natureza. É verdade que, antes dele, também Descartes sustentou a idéia (que já ouvi, ainda hoje, repetida por grandes médicos) que o animal é uma máquina. ${ }^{6}$ Ora, é preciso acabar com essa concepção de que a vida na natureza é algo axiologicamente vazio, algo neutro, bruto, que pode ser manipulado e, depois, pago em dinheiro, por nós, "os dignos". A vida é um valor. A vida é um valor em si, um valor ontológico. A permanente afirmação da dignidade da pessoa humana, sem valorização da vida em geral, é uma grande arrogância. No fundo, estão dizendo que o homem é o rei da criação. Cada um de nós, um reizinho. Vejo, em momentos de alucinação, a imensa procissão dos "dignos", caminhando pelo universo, todos com o rei na barriga, encabeçados pelos "grandes do mundo" e seguidos, depois, pela fila infindável dos bilhões de "dignos" (dignos deserdados) do planeta Terra.

\section{3. Ética e evolução biológica. A primeira emergência}

No mundo científico, ninguém mais tem dúvida de que não há uma radical separação, um abismo, entre o homo sapiens e os animais superiores. Na verdade, desde que a vida surgiu na Terra, há aproximadamente 4 bilhões de anos, temos um continuum no fluxo vital. Os seres vivos vêm se reproduzindo e, sem que muitas vezes desapareçam os seres de tipos anteriores, novos tipos de seres, cada vez mais complexos, foram aparecendo, até o surgimento do homo sapiens há aproximadamente 200 mil anos. No devir histórico, antes do homo sapiens, surgiram outros animais do gênero homo, como o homem de Neandertal, o homo erectus, o homo habilis que já eram bípedes e cultuavam os mortos; e talvez até mesmo falassem - aliás, não sei se os kantianos de hoje atribuem,

\footnotetext{
5 O Código Civil austríaco, o suíço e o alemão já não consideram os animais como "coisas". No B.G.B., no Livro II da Parte Geral, cujo título deixou de ser "Das Coisas" ou "Coisas" (Sachen) e hoje é "Das Coisas e dos Animais" (Sachen und Tiere), o § 90 prescreve: "Coisas no sentido da lei são somente os objetos corporais". E o §90a, que não existia, dispõe: "Os animais não são coisas. Eles são protegidos por leis especiais. A eles se aplicam as regras vigentes, para as coisas, se não houver disposição diversa".

6 Na Renascença e no séc. XVII, houve muita controvérsia sobre a questão do animal - máquina (Cf. GONTIER, Thierry. De l'homme à l'animal: paradoxes sur la nature des animaux. Montaigne et Descartes. Vrin: Paris, 1998). Há hoje muita literatura sobre "direitos" dos animais.
} 
ou-não, a dignidade da pessoa humana a esses hominídeos. Antes deles, ainda, apareceram os primatas, os mamíferos em geral, os marsupiais, os dinossauros e assim por diante até os seres unicelulares procariontes ("assim por diante", retroativamente).

$\mathrm{Na}$ evolução da vida, para efeitos de considerações éticas, limitando-nos ao mundo animal - podemos dizer que houve três "emergências" sucessivas, todas três com fundamentais conseqüências jurídicas. A primeira, que justamente é a do aparecimento da vida animal, fixa, para o homem, uma regra ética absoluta: todo ser humano tem direito a ver sua vida respeitada e a se defender. Vem daí os princípios jurídicos do respeito à vida e da legítima defesa; são regras básicas do "jus quod natura omnia animalia docuit" de Ulpiano. ${ }^{7}$ Ainda que as leis estabeleçam pressupostos e restrições à legítima defesa, nenhuma lei poderia prescrever que o ser humano não tem o direito de defesa da própria vida. Esse princípio é supra-constitucional; cria Direito subjetivo lato sensu e é de Direito natural no sentido próprio, porque a vida, repetimos, é um valor ontológico.

Por outro lado, não se expressam adequadamente, civilistas e constitucionalistas, quando se referem a "direito à vida", porque nem mesmo o titular do direito de defesa da própria vida tem literalmente "direito à vida". O direito é direito ao respeito e à defesa da vida. A expressão "direito à vida" dá impressão, por semelhança com outros direitos subjetivos, que é direito a obter a vida ou, o que é pior, direito sobre a vida, como quando se diz "direito à posse", "direito de posse", "direito à propriedade" e "direito de propriedade". Ora, não há direito a dispor da vida; somente há direito a ver a vida respeitada e a defendê-la. Nessa visão biocêntrica, não há lugar para a eutanásia (entendida no sentido próprio de ação contrária à própria vida) nem muito menos para o aborto, que é disposição de vida alheia. ${ }^{8}$

Como decorrência do valor ontológico da vida, surgem outras regras quer éticas quer jurídicas; assim, o respeito à integridade física e o respeito às condições mínimas de sobrevivência, no âmbito dos indivíduos, e o direito à proteção da natureza, no âmbito metaindividual. Daí também artigos de lei reconhecendo o direito a alimentos (até mesmo quando o alimentando é culpado de sua situação), o direito à casa própria, à saúde

\footnotetext{
Ulpiano: D. 1, 1, 1. São Tomás acompanha esse jus naturale de Ulpiano, dando-o num primeiro nível, como fundamento para a legítima defesa; na Questão 94, art. $2^{\circ}$, da $1^{\text {a }}$ Parte da $2^{\mathrm{a}}$ Parte da Suma Teológica, acrescenta um segundo nível, para o casamento e a criação dos filhos; e, depois, num terceiro nível, o que é próprio do homem. Há, aí, semelhança com nossa visão de três emergências biológicas.

8 Que o embrião concebido no ventre materno ou nele implantado é um ser humano que está na natureza como outro qualquer e que, portanto, têm direito a ver sua vida respeitada, é logicamente inquestionável. Já o embrião concebido artificialmente e que não foi implantado (o embrião pré-implantatório) merece respeito como ser vivo, mas parece excessivo considerá-lo como pessoa humana, no sentido filosófico. A decisão do STF sobre a constitucionalidade da Lei n. 11.105/2005 parece, pois, correta.
} 
e até mesmo, para subsistência, o direito à propriedade em geral. Paralelamente, há as leis de proteção aos animais e as ambientais em geral, todas fundadas no valor vida. Aqui as regras e os direitos subjetivos não são absolutos como o direito à defesa da vida mas, insistimos, são também resultantes da primeira emergência, da vida. Logicamente, surge, pois, uma primeira afirmação, que soará algo herética para os "dignos": o fundamento das regras e direitos acima lembrados é ético; o fundamento dessa ética, porém, não é religioso, cultural ou espiritual, é biológico.

4. A segunda emergência, solidariedade grupal e direito à realização dos impulsos vitais

A segunda emergência se constitui no aparecimento dos animais superiores, isto é, daqueles que possuem um sistema nervoso sofisticado, centralizado no cérebro, e em que há neurônios para percepção do ambiente externo e envio de informações, neurônios transmissores dessas informações e neurônios para emitir ordens de comportamento. ${ }^{9}$ A conseqüência desse aparato biológico é que esses animais decidem os movimentos que farão. As pessoas comuns, nos dias de hoje, costumam pensar que cachorros e outros animais são determinados de fora para dentro. Quando o proprietário de um cão de pêlo preto vê o animal deitado no pátio e percebe que a sombra foi se retraindo e os raios de sol começam a atingir o animal, pensa: "o meu cachorro vai se levantar e escolher um outro lugar para deitar". Isto de fato acontece e o proprietário imagina que o ato foi determinado pela conjunção sol, pêlo preto, calor, etc., sem decisão do cachorro. Isso não é verdade. Quando eu estou de carro na “Avenida Vinte e Três de Maio”, em São Paulo, e um motorista bate no veículo de outro, e ambos descem, discutem e o trânsito pára, penso: "daqui a 30 segundos os motoristas que estão parados vão começar a buzinar"; ora, isto de fato acontece, mas nem por isso nós consideramos que o ato de buzinar resultou das circunstâncias externas, sem uma decisão de cada qual. Na verdade, a previsibilidade de comportamento não significa que não haja processo interno de decisão. A convivência com cachorros, cavalos, gatos, porcos revelam que eles de alguma forma decidem as atitudes a tomar; alguns até mesmo hesitam, ficam em dúvida, são hamletianos - não sabem, por

\footnotetext{
KANDEL, Eric R. In Search of Memory: the Emergence of a New Science of Mind. Nova York - Londres: Norton, 2006. p. 66: <As três espécies de neurônios>: Sensory neurons, which are located in the skin and in various sense organs, respond to a specific type of stimulus from the outside world - mechanical pressure (touch), light (vision), sound waves (hearing), or specific chemicals (smell and taste) - and send this information to the brain. Motor neurons send their axons out of the brain stem and spinal cord to effector cells, such as muscle and gland cells, and control the activity of those cells. Interneurons, the most numerous class of neurons in the brain, serve as relays between sensory and motor neurons".
} 
exemplo, se obedecem ou-não a uma ordem e, pelo menos cachorros e gatos, sonham, tudo a demonstrar que têm vida interior, qualquer que seja o nome que se dê a isto. $\mathrm{O}$ mais impressionante são os relatos dos primatólogos sobre o comportamento dos macacos; estes não-só resolvem problemas com a utilização de instrumentos, como têm relações sociais entre si muito semelhantes às dos seres humanos. ${ }^{10}$

Todos esses animais superiores, inclusive o homem, parecem ter obtido mais sucesso que os demais, na luta pela sobrevivência na natureza, em virtude de um fator biológico que é o da solidariedade grupal. Esses animais vivem em "sociedade". No mundo da atividade pecuária, sabe-se perfeitamente que bois no pasto se comportam como um conjunto; vão e voltam como um todo, observam sempre juntos o que faz o peão e, se o peão laça um deles, para cuidados veterinários, os outros ficam nervosos e procuram até mesmo ajudar o companheiro que lhes parece estar em perigo. Em Mato Grosso, em regiões onde ainda há onça ou lobo-do-mato, o gado de criar se organiza em círculos concêntricos, quando em perigo; os bezerros ficam no círculo menor, as vacas se põem no círculo médio e, finalmente, no último círculo, o maior, ficam os touros, que permanecem rodando em volta do rebanho, para evitar que o predador pegue uma rês mais fraca. Os macacos, por sua vez, caçam em conjunto de forma muito organizada, distribuindo quem deve ir pela direita ou pela esquerda para acurralar a caça. Essa solidariedade é a mesma que as pessoas de uma nacionalidade, especialmente quando em terra estrangeira, sentem umas em relação às outras. As torcidas de futebol revelam bem esse sentimento inteiramente biológico da solidariedade grupal. Essa solidariedade não deve ser confundida com a solidariedade universal, isto é, obtida racionalmente, entre todos os seres humanos, independente de origem ou condição, de que falaremos por ocasião da exposição sobre a terceira emergência. A solidariedade de que estamos agora tratando é emocional, um impulso físico de defender os semelhantes; esta solidariedade é própria dos animais superiores e também se revela nos seres humanos, dando origem a muitas regras jurídicas.

A manifestação jurídica mais clara da solidariedade grupal é a da família, com as normas desse direito. ${ }^{11}$ Outra, importante, é a do direito de se associar (C.R., art. $\left.5^{\circ}, \mathrm{XX}\right)$. O próprio direito de alimentos que já vimos estar ligado à primeira emergência,

\footnotetext{
${ }_{10}$ Cf. DE WAAL, Frans. Good Natured - the origins of right and wrong in humans and other animals. Cambridge - Londres: Havard University Press, 1996. passim.

11 Na família, há, além de empatia, simpatia. De Waal distingue "empatia", sensação emocional de identidade de A para com a situação de B, de modo que A, até mesmo por razão egoístas, tenta ajudar B, de "simpatia", que é um nível de identidade mais avançado. Cf. DE WAAL, Frans. Primates and Phisophers. Princeton: Princeton University Press, 2006. V. p. XIII da Introdução de Ober e Macedo".
} 
se encarado do lado do alimentando, pode também ser visto pelo ângulo do alimentante, mas relações de parentesco, quando então estará fundado na segunda emergência; isto é, se tivermos a visão clara de que os alimentos surgem, num primeiro momento lógico, como direito para quem necessita e que, somente num segundo momento, é que vamos vê-lo como dever, quando será preciso investigar quem deve, percebemos que o Direito se baseia na sobrevivência mas o dever, entre parentes, está fundado na solidariedade grupal (ou seja, repetimos, o direito de alimentos existe por força da primeira emergência; esse direito nasce da necessidade. ${ }^{12}$ Logicamente, é somente num segundo momento que é preciso saber quem atenderá ao direito e aí juridicamente temos que saber quem deve pagar os alimentos; nesse caso, a decisão da regra jurídica, entre parentes, vai vir com fundamento na segunda emergência, no pensamento da solidariedade grupal).

Uma segunda característica, que importa para o mundo jurídico, na segunda emergência, é a relativa ao direito de realização dos impulsos vitais. Trata-se aqui de um plus em relação ao simples instinto de sobrevivência. Estamos pensando agora no direito a procriar, a se desenvolver, a ampliar o conhecimento e no direito ao prazer. Com mais elegância - mas com muito menos força, porque a palavra "felicidade" não tem conteúdo preciso - americanos tratam desse direito com a expressão "direito à felicidade". ${ }^{13}$ Independentemente do nome, a verdade é que ceteris paribus entre duas situações, uma de satisfação na auto-realização e outra contrária, de renúncia ou sofrimento, nós, como os animais superiores, optamos pela primeira. Esse fundamento biológico dá origem ao princípio jurídico da autonomia da vontade, eis que por ele compete a nós fazermos o que nos satisfaz e realizarmos o negócio jurídico que nos interessa. Sob esse ângulo, o individual, o negócio jurídico, seja contrato, ato unilateral como testamento, promessa de recompensa, etc., ou outro qualquer, é instrumento de autodeterminação. Está reconhecido na Constituição e no Código Civil. ${ }^{14}$

\footnotetext{
12 A necessidade quer como criadora de direito quer como fonte de obrigação - por exemplo, no dever de socorro, não tem sido devidamente considerada nos manuais de Direito Civil. Cf., porém, a monografia de SAYAG, Alain. Essai sur le besoin créateur du droit. Paris: L.G.D.J., 1969.

$13 \mathrm{Na}$ "Declaração de Independência", americana, entre os "direitos inalienáveis" de todos os homens, criados iguais, estão a vida, a liberdade e a busca da felicidade ("pursuit of happiness"). Por sua vez, na "Lei Fundamental" da antiga República Federal Alemã, a primeira alínea do art. $2^{\circ}$ prescreve: "Todos têm o direito ao livre desenvolvimento da sua personalidade, desde que não violem os direitos de outros e não atentem contra a ordem constitucional ou a lei moral".

14 No Código Civil, o negócio jurídico está, de maneira expressa, nos arts. 104 a 184. Na Constituição, o negocio jurídico está implicitamente no art. $1^{\circ}$, IV, e n. 170, ambos por meio da valoração da noção econômica de "livre iniciativa" que naturalmente há de se manifestar por meio dos contratos, que é espécie de negócio jurídico.
} 
Infelizmente, a "moral de escravos", como Nietzsche a chamou, e dada por ele erradamente como própria do Cristianismo, não favorece a auto-realização e, pelo contrário, atribui indevidamente conotações positivas para as situações contrárias, de renúncia e sofrimento. Essas situações, porém, em si, não têm valor, enquanto a realização dos impulsos vitais, inclusive o prazer, sim. ${ }^{15}$ "Virtudes", como obediência, austeridade, humildade, conformismo e outras parecidas não têm, em si, mais valor, religioso ou moral, do que as qualidades opostas. Esta é uma questão delicada, mas o possível valor daquelas "virtudes" é indireto e resulta dos fins que o agente visa alcançar. O homem deve, pois, dominá-las como o cavaleiro, o cavalo (Nietzsche). As referidas "virtudes" valem somente como exercício, preparo existencial do ser humano para obter algum outro fim, que este sim poderá ter ou-não valor em si. Do ponto de vista da religião católica, por exemplo, apesar do engano de muitos na matéria, aquelas "virtudes" não são essenciais, porque o que importa é o amor, de tal forma que qualquer ato, seja na forma de obediência ou de desobediência, de alegria ou tristeza, de humildade ou soberba, se for sem amor, é mau e, se for com amor, é bom. "A la tarde te examinarán en el amor" (S. João da Cruz).

No campo da ética, o direito à realização dos impulsos vitais é "legítimo" e as leis seguem esse "legítimo". Como dissemos, o negócio jurídico está nele fundamentado; todavia, é conveniente lembrar que, como há também no negócio jurídico forte apelo ao "social", isto é, à sociedade, o negócio jurídico tem uma segunda vertente relacionada à palavra e à cultura, à exigência social de fidelidade à palavra dada, temas que já são próprios da terceira emergência, como veremos. Como quer que seja, todo o campo do negócio jurídico, no fundo, consubstancia o reconhecimento legal do impulso biológico, em forma socialmente consagrada, do direito à satisfação dos impulsos vitais de autorealização. Esse direito, como todos os demais, exceto o da defesa da vida da primeira emergência, não é absoluto e deve ser compatibilizado, conforme as regras respectivas, com os direitos alheios.

Os direitos de segunda emergência, isto é, os fundados na solidariedade grupal e no direito à auto-realização, podem entrar em conflito entre si, eis que não têm o mesmo fim; podem, também e principalmente, entrar em conflito com o direito resultante da primeira emergência. Afinal, as linhas de atuação da ética biológica não são convergentes; são somente justapostas no mesmo agente. Essa situação, quando se trata da terceira emergência, leva as coisas a se complicarem ainda mais, exigindo todo o sistema

\footnotetext{
15 NIETZSCHE, Friedrich. Par-delà bien et mal. Tradução de Cornelius Heim. Paris: Gallimard, 1971. § 260, p. 183 - mas a idéia é generalizada também em outras obras do Autor. (Cap. Moral de senhores e moral de escravos).
} 
jurídico, para prevenir e eliminar conflitos. Por ora, ficando somente nos dois primeiros momentos da evolução, somos de opinião que, sempre ceteris paribus, devem prevalecer em caso de conflito, os direitos da primeira emergência sobre os da segunda. Não temos, porém, posição conclusa, em caso de conflito dos direitos de segunda emergência entre si.

5. A terceira emergência, igualdade de tratamento e solidariedade universal

$\mathrm{Na}$ ordem histórica da evolução, chegamos agora ao aparecimento do homo sapiens. O que ele possui a mais em relação aos demais animais superiores diz respeito à palavra; é a capacidade de pensar com palavras e se comunicar com palavras (ratio et oratio, dois vocábulos que, em grego, estavam reunidos em um só, logos). Todo homem supõe no outro a existência de uma mente semelhante à sua. Há outras faculdades que costumam ser dadas como exclusivas do ser humano, como a razão em geral, a vontade e a auto-consciência que, porém, a nosso ver, os animais, especialmente os chipanzés e orangotangos, também possuem. Vamos dar como pacífica, por causa da extensão deste estudo, a questão da razão e da vontade. Quanto à auto-consciência, as observações de Anton Pertielje, em 1922, depois Wolfang Köhler, em 1925, e outros, até as interessantes experiências de Gordon Gallup, na década de 70, demonstraram que chipanzés e orangotangos se reconhecem no espelho. ${ }^{16}$ Todavia, como se sabe, até mesmo os mais inteligentes dos nossos primos não têm linguagem e, assim, encontram um obstáculo intransponível para a transmissão eficaz e crescente de conhecimento. Entre os macacos maiores, que os americanos denominam "apes", são freqüentes as ações de adultos ensinando aos mais jovens técnicas de utilização de instrumentos e modos de evitar perigos. Todavia, essa transmissão de conhecimento é evidentemente muito precária

\footnotetext{
${ }^{16}$ De Waal: "While almost all visually oriented mammals initially try to reach or look behind a mirror, only two nonhummam species - chimpanzees and orangutans - seem to understand that they are seeing themselves. The special status of these apes has been recognized for a long time. (...) Compelling evidence was derived in the 1970s from elegant experiments by Gordon Gallup, an American comparative psychologist. An individual unknowingly received a dot of paint in a specific place, such as above the eyebrow, invisible without a mirror. Guided by their reflection, chimpanzees and orangutans - as well as children more than eighteen months of age - rubbed the painted spot with their hand and inspected the fingers that had touched it, recognizing that the coloring on the reflected image was on their own face. Other primates - and younger children - failed to make this connection. Gallup went on to equate self-recognition with self-awareness, and this in turn with a multitude of sophisticated mental abilities. The list encompassed attribution of intention to others, intentional deception, reconciliation, and empathy. Accordingly, humans and apes have entered a cognitive domain that sets them apart from other forms of life" (DE WAAL, Frans. Good Natured - the origins of right and wrong in humans and other animals. Cambridge - Londres: Havard University Press, 1996. p. 67)”.
} 
por falta de palavras. Sua cultura é mínima; falta-lhes o logos, que é justamente o que vai permitir o desenvolvimento da cultura humana e das civilizações.

Apesar do vulto que tem a cultura para o ser humano e do papel da linguagem na nossa formação, são disposições fisiológicas do nosso cérebro e de nossos órgãos que permitem a fala. A mente humana não é uma tabula rasa em que as impressões vão se depositando e constituindo conhecimento por influência exclusiva do meio. Há predisposições para isso, embora, como é evidente, cada criança vá aprender, no seu meio, sua cultura e sua língua. ${ }^{17}$

Do ponto de vista ético, na terceira emergência, há que considerar dois princípios, que são então próprios do homo sapiens e do mundo da cultura: a exigência de igualdade no tratamento das situações iguais e a solidariedade universal no sentido de empatia, por sermos todos da mesma espécie. O primeiro quase que se confunde com o que se entende por justiça e inclui as expectativas de reciprocidade. Nele prevalece uma regra formal, à moda de Kant, que é a de que às situações iguais devem ser aplicadas soluções iguais. Formulada, juridicamente, a regra corresponde ao senso de justiça e, na evolução, foi útil ao homo sapiens, para resolver litígios. A Justiça, assim, não é uma deusa mas sim uma vantagem da espécie humana. O segundo resulta numa espécie de identificação com todos, independente da etnia, idioma, etc - bem evidente na Declaração dos Direitos do Homem, da ONU, de 1948. Uma boa prova dessa espécie de igualdade biológica entre todos os seres humanos, está no estudo de pesquisadores americanos, em especial, Ekman, que isolaram sete expressões faciais que, independentemente da cultura ou outras condições de cada observador, têm, para todos o mesmo significado; são fotografias de fisionomias de medo, angústia, alegria, tristeza, surpresa, desprezo e nojo. ${ }^{18}$ Os dois princípios citados nesse parágrafo estão no terreno da ética e do Direito de que todos falam, mas insistamos: seus fundamentos são biológicos. As formas pelas quais, depois, historicamente, cada cultura vai expressar esses princípios da espécie humana vão depender de outras circunstâncias, resultando na diversidade de civilizações.

Nesse ponto, quase concluindo, seria interessante voltar à questão dos conflitos entre direitos e normas originários das três emergências - conflitos que aparentemente não deveriam existir já que o fundamento geral é a natureza. Ora, a primeira explicação está na própria diferença de conteúdo, entre os impulsos biológicos

\footnotetext{
${ }^{17}$ Cf. PINKER, Steven. "The Blank Slate”; sua tese é também a de Noam Chomsky, Jerry Fodor, etc., com divergências.

18 Infelizmente, neste artigo, não é possível a reprodução das sete fisionomias. Veja-se, porém, Kandel, obra citada na nota 9 , onde há a reprodução (p. 386).
} 
da primeira emergência, da segunda e da terceira. Animais primitivos como os lagartos vão defender sua vida, com muito pequeno ou nenhum impulso de solidariedade grupal ou de satisfação de outros instintos diversos do de sobrevivência; já um animal superior, na segunda emergência, pode vir a se encontrar em conflito existencial, por exemplo, entre defender-se a qualquer custo ou defender o seu grupo. Certamente o leitor percebe que pode haver gradação dos riscos, isto é, ser maior ou menor a possível perda da vida, e daí, no exame dos pesos, eventual opção pela solidariedade grupal. Ademais, a verdade é que tanto os homens quanto os animais superiores muitas vezes arriscam suas vidas em prol do grupo, por exemplo, em caçadas ou guerras; há de ser por erro de avaliação dos animais ou por força da cultura do ser humano. Depois, no nosso caso, em mais um passo para o alto, é evidente que as regras do homo sapiens, formuladas culturalmente, podem também entrar em conflito com as da segunda ou da própria terceira emergência. Na regra da igualdade formal, por exemplo, muitos cidadãos brasileiros hesitariam entre atribuir vantagens econômicas a povos mais pobres, com sacrifício dos interesses nacionais, até porque muitos compatriotas já se sentem prejudicados frente a povos mais ricos. No fundo, há aí conflito entre o que é nacional e o que é internacional, entre solidariedade grupal (segunda emergência) e solidariedade universal (terceira emergência).

\section{Conclusão}

A idéia hoje generalizada de dignidade da pessoa humana deve sofrer um re-estudo. Seu fundamento teórico parece ser o dualismo "corpo e alma", que provém da filosofia de Platão e Aristóteles, foi aceita por muitos cristãos e, em seguida, pela filosofia moderna (Descartes, Kant), mas no qual a articulação entre os dois termos é mal explicada. Ademais, nessa visão, os animais não têm alma, nem muito menos o restante da natureza, reduzido à condição de coisa pelo personalismo ético. A ideologia da dignidade da pessoa humana como vem sendo sustentada não-só não corresponde ao conhecimento atual da Ciência, que fornece à ética fundamento biológico, como também não contribui para a mudança da mentalidade coletiva que a defesa da vida exige hoje.

São Paulo, 20 de junho de 2008.

\section{Referências}

DE WAAL, Frans. Good natured: the origins of right and wrong in humans and other animals. Cambridge / Londres: Havard University Press, 1996. 
DE WAAL, Frans. Primates and phisophers. Introdução de Ober e Macedo. Princeton: Princeton University Press, 2006.

FRANÇA, Rubens Limongi. Direito civil constitucional. Revista do Tribunal de Justiça do Pará, Pará, n. 55, 1992.

GONTIER, Thierry. De l'homme à l'animal: paradoxes sur la nature des animaux. Montaigne et Descartes. Vrin, Paris, 1998.

JONAS, Hans. Le principe responsabité: une éthique pour la civilisation technologique. Tradução de Jean Greisch. Paris: Flamarion, 2000.

KANDEL, Eric R. In search of memory: the Emergence of a New Science of Mind. Nova York / Londres: Norton, 2006.

KANT, Emanuel. Des fondaments de la métaphysique des moeurs. Tradução de J. Barni. Paris: Livr. Philosophique de Ladrange, 1848.

LARENZ, Karl. Derecho civil: parte general. Tradução de Miguel Izquierdo y Macías. PicaveaMadri: Ed. Revista de Derecho Privado, 1978.

NIETZSCHE, Friedrich. Par-delà bien et mal. Tradução de Cornelius Heim. Paris: Gallimard, 1971.

REALE, Miguel. Apresentação do Projeto de Código Civil ao Ministro da Justiça, 1984.

SAYAG, Alain. Essai sur le besoin créateur du droit. Paris: L.G.D.J., 1969.

TOMÁS DE AQUINO, São. Suma Teológica. 1. parte da 2. parte. 